\title{
Molecular Cloning, Characterization and Expression Analysis of MhRAR1 Gene from Malus Hupehensis
}

\author{
Zhang Ji-Yu, Guo Zhong-Ren \\ Institute of Botany, Jiangsu Province and the Chinese Academy of Sciences, Nanjing, China
}

Email address:

maxzhangjy@163.com (Zhang Ji-Yu), zhongrenguo@cnbg.net (Guo Zhong-Ren)

To cite this article:

Zhang Ji-Yu, Guo Zhong-Ren. Molecular Cloning, Characterization and Expression Analysis of MhRARl Gene from Malus Hupehensis. Journal of Plant Sciences. Vol. 3, No. 2, 2015, pp. 85-91. doi: 10.11648/j.jps.20150302.17

\begin{abstract}
A novel RARl gene, designated MhRARl, was cloned by the methods of RT-PCR and RACE from Malus hupehensis. The full length sequence of MhRARI is $1065 \mathrm{bp}$ with an open reading frame of $678 \mathrm{bp}$, encoding a protein of 225 amino acids. As found in other plant RAR1 proteins, sequence alignment showed that MhRAR1 protein contains two CHORD domains and one plant-specific CCCH domain. In addition, the MhRAR1 contains conserved strings of invariant cysteine and histidine residues within the CHORD domains and $\mathrm{CCCH}$ domain. These results suggested that MhRAR1 protein from $M$. hupehensis might share the similar function with the Arabidopsis thaliana RAR1 and Hordeum vulgare RAR1, and is an important component of R gene-mediated disease resistance. Phylogenetic analysis revealed that MhRAR1 was closely related to Ricinus communis RAR1. The analysis by qRT-PCR revealed that the expression of MhRARl gene was higher in leaves than that in stems and roots. SA, MeJA and ACC treatment induced MhRARl expression in stems and roots, but not in leaves. Expression of MhRARl was weakly induced in M. hupehensis after infection with Botryosphaeria berengeriana. The cloning and characterization of the MhRARl gene will be useful for further studies of biological roles of MhRARI in plants.
\end{abstract}

Keywords: Malus hupehensis, MhRAR1, cDNA Cloning, Expression Pattern

\section{Introduction}

Plants are frequently attacked by various disease pathogenesis with complicated strategies colonizing their hosts, and have evolved defense mechanisms to protect themselves effectively from microbial pathogens. Plants various resistance proteins ( $\mathrm{R}$ proteins) activate resistance responses including rapid ion fluxes, generation of reactive oxygen species (ROS), production of antimicrobial compounds, and the accumulation of salicylic acid (SA) which was crucial for the induction of systemic acquired resistance (SAR). These responses are accompanied by the hypersensitive response (HR), localized programmed cell death at the site of pathogen invasion [1].

RAR1 (Required for Mla12 resistance), which was a crucial component of resistance conferred by many $\mathrm{R}$ proteins [2,3], play a key role in disease resistance of plants. Arabidopsis rar 1 mutants are defective in R-protein mediated resistance against several bacterial (Pseudomonas) and oomycete (Peronospora) pathogens [4,5]. Rar1 mutants fail to accumulate ROS or mount the HR in barley [6]. In the past several decades, many studies have been done to discover the molecular function of
RAR1 protein in plants. Numbers of researches have been carried out in the model plants such as Arabidopsis [4,7,8], barley[3, 9-11], tobacco[12] and so on. However, none of work was done in woody plants especially in fruit trees such as apple.

The plant hormones SA, MeJA and ET are three types of signalling mediators that activate the plant defence response against pathogen attack $[13,14]$. In general, SA and JA/ET are thought to regulate two different signal transduction pathways in plant disease resistance. SA and JA/ET signalling pathways and the cross-talk between them have been studied in various plants [15-17]. To determine whether exogenous application of these stimuli could induce the expression of MhRAR1 gene, Malus hupehensis were treated with SA, MeJA and ACC.

Malus hupehensis, common names Hupeh crab or tea crabapple, is a species of flowering plant in the apple genus Malus of the family Rosaceae, native to Japan and Taiwan and province of China. It is a vigorous deciduous tree growing to $12 \mathrm{~m} \mathrm{(39} \mathrm{ft})$ tall and broad, with pink buds opening to fragrant white blossom in Spring, and bright red, cherry-sized 
crab-apples in the Autumn. M. hupehensis was an apple rootstock that is tolerant to various apple pathogens [18]. Here, we isolated and functionally characterised of a M. hupehensis RARl gene. To better understand MhRARl gene functions, we also analysed the expression of MhRARl in response to plant hormones, such as SA, MeJA, and ACC in different tissues of $M$. hupehensis, and in response to biotic stress apple ring spot pathogenesis Botryosphaeria berengeriana.

\section{Materials and Methods}

\subsection{Plant Materials and Bacterial Strains}

M. hupehensis plants were subcultured in vitro in Murashige and Skoog (MS) medium supplemented with 6-benzylaminopurine (6-BA, $0.5 \mathrm{mg} / \mathrm{L})$ and naphthalene acetic acid (NAA, $0.1 \mathrm{mg} / \mathrm{L}$ ) and cultured under a 16-hour light $\left(25^{\circ} \mathrm{C}\right) / 8$-hour dark $\left(25^{\circ} \mathrm{C}\right)$ cycle. Escherichia coli strain $\mathrm{DH} 5 \alpha$ cells were used for the cloning of MhRAR1, and propagation of all the recombinant plasmid vectors. The Pyk2478 vectors were used for the construction of plant expression vectors of the $R A R 1$ gene.

\subsection{Treatment of M. hupehensis with $S A, M e J A$ and $A C C$ and Apple Ring Spot Pathogen}

Three weeks old $M$. hupehensis in vitro plant leaves were sprayed with $0.1 \mathrm{mM} \mathrm{SA} \mathrm{(Sigma),} 0.02 \mathrm{mM} \mathrm{MeJA} \mathrm{(Sigma)} \mathrm{and}$ $0.01 \mathrm{mM}$ ACC (Sigma) for 4, 12 and 48h, respectively, with water treatment as a control. Each treatment group consisted of three plants. Then, the leaves, stems and roots were harvested and frozen in liquid nitrogen. Tissues were stored at $-70^{\circ} \mathrm{C}$ until use. For apple ring spot pathogen inoculation $(B$. berengeriana), $M$. hupehensis tissue culture plants were rooted after four weeks. Abaxial leaf surfaces were sprayed with freshly collected sporangia propagated in potato dextrose agar (PDA) media and resuspended in water at approximately $1.0 \times 10^{6}$ spores $\cdot \mathrm{mL}^{-1}$. Leaves were collected at different time points and immediately frozen in liquid nitrogen.

\subsection{Extraction of Total RNA and Clone of MhRAR1}

PCR was performed with the primers RF1 and RR1 (Table 1) derived from the conserved sequence region of RAR1 using a complete cDNA library [19] in order to isolate a partial cDNA fragment (554bp) of the MhRAR1gene. Then, using a sequence obtained from the initial cDNA fragment, new gene-specific sense and antisense primers were designed for the 5'- and 3'- rapid amplification of cDNA ends (RACE) reactions (Table 1). The missing 3' and 5' sequences were obtained by RACE with SMARTTM RACE CDNA Amplification Kit (Clontech Laboratories, Inc. No. 634902). The conserved, 3' and 5' sequences were assembled using the DNAMAN software. To verify the assembled sequence, PCR was performed using the primers RF3 and RR3 (Table 1) from the complete cDNA library to amplify the open reading frame (ORF) of MhRAR1. Genomic DNA was extracted from leaves and treated with RNase I as described by Tong et al.[20]. MhRAR1 gene cloning from genomic DNA was performed as above using the primes RF3 and RR3 (Table 1). The PCR products were cloned into a pMD19-T vector (TaKaRa) and sequenced by the Shanghai Invitrogen Biotechnology Company Ltd.

The amino acids sequence of MhRAR1 was deduced and analyzed using ProtParam tool (http: //cn.expasy.org/tools/protparam. html). Nucleotide and protein sequence similarity analyses were carried out at the NCBI server using BLAST programs (http://www.ncbi.nlm.nih.gov/BLAST/). Amino acid alignment sequences of RAR1 homologues were downloaded from GenBank and the alignment of the amino acid sequences with that of MhRAR1 was performed using BioEdit software. A comparative phylogenetic tree was then constructed using MEGA software version 4.0 with the Neighbour-Joining method [21] and 1000 replicates were used for bootstrap test. The tree was then visualised using the tree view package[22].

\subsection{Gene Expression Analysis of MhRAR1 in M. hupehensis Using Real-Time Quantitative RT-PCR ( $q R T-P C R)$}

Total RNA isolation were performed as described by Cai et al. [23] and DNase I treatment was performed according to the manufacturer's protocol. First strand cDNA was synthesised with the ReverTraAce qPCR RT Kit (TOYOBO, Code No.: FSQ-101) according the manufacturer's instructions. QRT-PCR analyses with a pair of primers (Table 1) were performed to determine the tissue-specific expression (leaf, stem and root) and expression profiles of MhRARl after various treatments. Normal PCR reactions were performed to ensure gene-specific amplification using the primers BRF1 and BRR1 to amplify the MhRAR1 gene. A single PCR fragment with the expected size was amplified, suggesting that the primers were suitable for qRT-PCR analyses. To confirm the expected fragment of the MhRARl gene, the resulting PCR product was cloned and sequenced. All samples were harvested and three biological replicates were run independently. M. hupehensis tubulin was amplified with a pair of primers and used as the housekeeping gene for the qRT-PCR analyses. Templates were the $10 \times$ diluted cDNAs from each sample. The reaction protocol was as follows: $1 \mu \mathrm{L}$ of 10 -fold diluted cDNA, $0.3 \mu \mathrm{L} 10 \mathrm{pM}$ of each primer (Table 1), $10 \mu \mathrm{L}$ SYBR ${ }^{\circledR}$ Premix Ex Taq ${ }^{\mathrm{TM}}$ (Perfect Real Time) (TaKaRa Code: DRR041A) and $8.4 \mu \mathrm{L}$ of sterile double distilled water. The thermal conditions were: $95^{\circ} \mathrm{C}$ for $4 \mathrm{~min}$, $95^{\circ} \mathrm{C}$ for $20 \mathrm{~s}, 58^{\circ} \mathrm{C}$ for $20 \mathrm{~s}$ and $72^{\circ} \mathrm{C}$ for $43 \mathrm{~s}$ for 40 cycles. Dissociation curves from $55^{\circ} \mathrm{C}$ to $95^{\circ} \mathrm{C}$ were generated for each reaction to ensure specific amplification, along with verification by gel electrophoresis. The qRT-PCRs were performed using a 7300 Real-Time PCR System (Applied Biosystems, Foster City, CA, USA). The relative levels of genes respective to control Mhtubulin mRNAs were analysed using the 7300 system software and the $2^{-\Delta \Delta^{\mathrm{Ct}}}$ method [24]. Data analyses were conducted using SPSS version 17.0 statistical software. For all analyses, the level of significance between different time points was set at $\mathrm{P}<0.05$. 


\subsection{Subcellular Localisation of the MhRAR1-EGFP Fusion Protein}

Subcellular localisation of MhRAR1 was assayed according to the method of Wang et al.[25]. For generating the MhRAR1-GFP fusion construct, the MhRARl ORF was amplified with a forward primer YXRAF1 containing a
BamH I site and a reverse primer YXRAR1 containing an EcoR I site (Table 1). The resulting PCR products were cloned into the pMD19-T simple vector (TaKaRa) and sequenced. The entire ORF of the MhRARl gene was inserted into the plasmid Pyk2784-EGFP which included enhanced green fluorescent protein.

Table 1. Primers used for this paper.

\begin{tabular}{lll}
\hline Primers name & Sequence [5'-3'] & Usage \\
\hline RF1 & ACTTGCGACGCCATGTTC & Cloning of MhRAR1 conserved sequence \\
RR1 & TCGCAACATTTCCACCCTC & 3'RACE \\
RF2 & AGAGAAAGATAACCACGAGAATGC & 5'RACE \\
RR2 & GGAGCAGAAGTGCCTTGATCGTCAGTAAT & PCR amplification of MhRAR1 ORF \\
RF3 & ACACTAGTGGATGGAGGGTC & Expression analysis for MhRAR1 \\
RR3 & GGTACCTTAAGATACCGGGT & Housekeeping gene \\
BRF1 & TGATATAAACCAGCCCCAGACG & \\
BRR1 & CACAGCACTTCCACCCTCTC 1 & Vector construction of Subcellular localization \\
BAR1 & AGGTCCATCCATTGTCCACAG & \\
YXRAF1 & TGCCAACCAAACTGACTTCAC & \\
YXRAR1 & ACGGATCCGGATGGAGGGTC & \\
\hline
\end{tabular}

\section{Results}

\subsection{Analysis of the MhRARI Gene Sequence and the Predicted Protein}

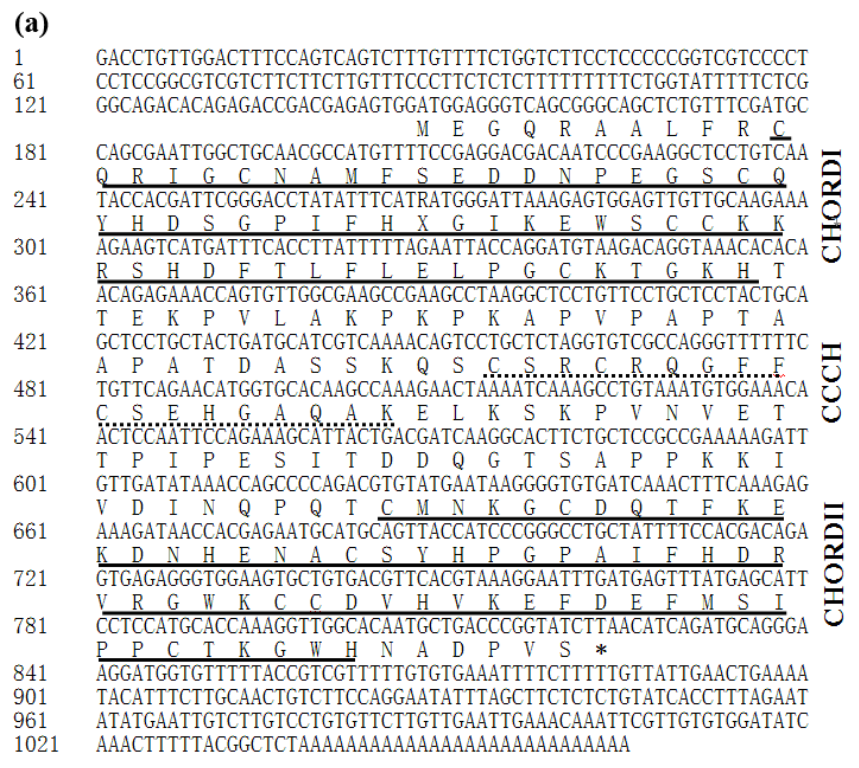

(b)

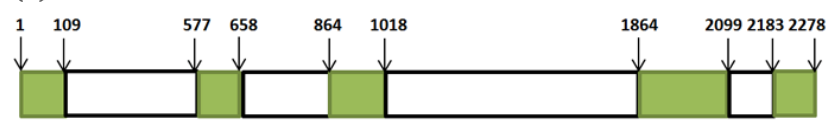

Fig. 1. The structure of MhRAR1 gene and protein. (a) The nucleotide and deduced amino acid sequences of cloned MhRAR1. The protein sequence is indicated by one letter code below the nucleotide sequence. *indicate the stop codon. (b) Schematic diagram of MhRARl gene. Reseda indicated the exons and White indicated the introns.

A full-length $1,065 \mathrm{bp}$ of $\mathrm{M}$. hupehensis $R A R 1$ was cloned using the methods of RT-PCR and RACE. It contained an open reading frame (ORF) of $678 \mathrm{bp}$ encoded a protein of 225 amino acids. The cDNA had a 5'-untranslated region (UTR) of 147 nucleotides, a 3'-UTR of 240 nucleotides including a stop codon (TAA) (Fig. 1a). The calculated molecular mass was $24.90 \mathrm{kDa}$, and the estimated isoelectric point (pI) of this protein was 7.51. The MhRARl cDNA sequence has been submitted to the NCBI GenBank as accession number FJ593502. The MhRAR1 genomic DNA sequence from start to stop codon was $2278 \mathrm{bp}$, and there were five exons and four introns in the complete coding region of MhRARl when the cDNA sequence and genomic DNA sequence were compared (Fig. 1b).

\subsection{Multiple Sequences Alignment and Phylogenetic Analysis}

A search in the GenBank database, using the BLASTP program, revealed that the predicted MhRAR1 deduced amino acid of M. hupehensis exhibited high similarities with those of the $M$. domestica (identities $97 \%$ ), Fragaria vesca subsp.vesca (identities $84 \%$ ), Prunus mume (identities $84 \%$ ) and Ricinus communis (identities $74 \%$ ). Similar to A. thaliana [4], barley and tobacco [12], there were two cysteine and histidine-rich $\mathrm{Zn} 2+$-binding domains (designated as CHORD) and one plant-specific conserved Cys residues and a His residue $(\mathrm{CCCH})$ domain in MhRAR1 protein (Fig.2). In addition, the MhRAR1 contains conserved strings of invariant Cys and His residues within the CHORD domains (Fig.2). The amino acid sequences outside the CHORD and $\mathrm{CCCH}$ domains are significantly different among plant PAR1 proteins (Fig.2). To determine the phylogenetic relationship between MhRAR1 and other plant RAR proteins, a phylogenetic tree was constructed, revealing that MhRAR1 was closely related to MdRAR1, FvRAR1 and PmRAR1 (Fig. $3)$. 


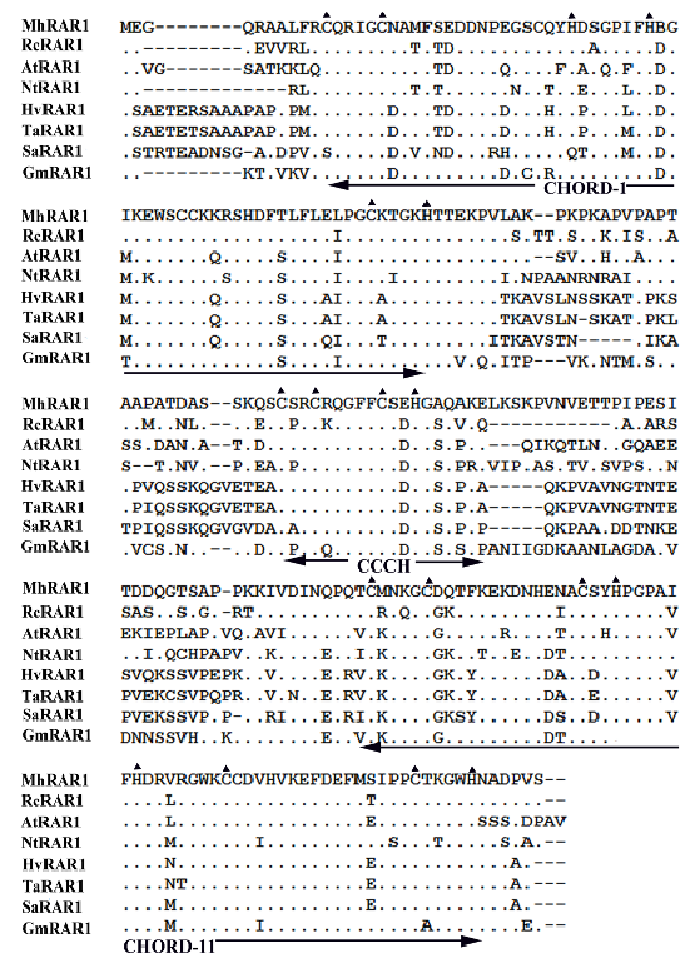

Fig. 2. Amino acid sequence comparison of the predicted Malus hupehensis RAR1 protein with the other plant species Rar1. CLUSTALW produced alignment was formatted using BioEdit software. Conservative substitutions are shaded in dot mark. Two conserved CHORD domains (CHORD-I and II) and one conserved CCCH domain are shown. Triangle $(\mathbf{\Delta})$ indicate invariant conserved cystein and histidine residues within the CHORD and $\mathrm{CCCH}$ domains. The accession numbers of plant RAR sequences are as follows: MhRAR1: Malus hupehensis RAR1 (gbACT98264); RcRAR1: Ricinus communis RAR1 (ref XP002510896); AtRAR1: Arabidopsis thaliana RARI (dbjBAB11239); NtRAR1: Nicotiana tabacum RAR1 (gbAAM62409); HvRAR1: Hordeum vulgare RAR1 (gbAAF18432); TaRAR1: Triticum aestivum RAR1 (gbABN13684); SaRAR1: Saccharum hybrid cultivar RARI (gbACX68653); GmRAR1: Glycine max RAR1 (gbACI31548).

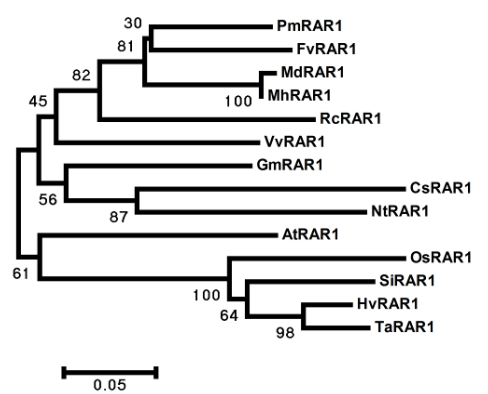

Fig. 3. Phylogenetic relationships of MhRAR1 with other plant RAR1. Phylogenetic tree was constructed using MEGA software version 4.0 with the Neighbour-Joining method (Tamura et al. 2007) and 1000 replicates were used for bootstrap test. The tree was then visualised using the tree view package (Page 1996). The accession numbers of plant RAR sequences are as follows: MhRAR1: Malus hupehensis RAR1 (gbACT98264); RcRAR1: Ricinus communis RAR1 (ref XP002510896); AtRAR1: Arabidopsis thaliana RAR1 (dbjBAB11239); NtRAR1: Nicotiana tabacum RAR1 (gbAAM62409); HvRAR1: Hordeum vulgare RAR1 (gbAAF18432); TaRAR1: Triticum aestivum RAR1 (gbABN13684); GmRAR1: Glycine max RAR1 (gbACI31548); MdRAR1: Malus domestica RAR1 (ref XP008376437); FvRAR1: Fragaria vesca subsp.vesca RAR1 (ref XP004308155); PmRAR1: Prunus mume RAR1 (ref XP008234345); VvRAR1: Vitis vinifera RAR1 (ref XP002269178); SiRAR1: Setaria italic (ref XP001267761); OsRAR1: Oryza sativa RAR1 (gb BAD27802); CsRAR1: Cucumis sativus (ref XP004159991).

\subsection{Tissues Expression of MhRAR1 in M. hupehensis}

QRT-PCR was performed to measure the MhRARl gene expression in different tissues of $M$. hupehensis. The dissociation curves were analyzed to determine the amplification specificity for MhRAR1 and Mhtubulin. Only one peak existing in the dissociation curves for both MhRARl and Mhtubulin gene, indicating that the amplifications were specific. The results showed that the mRNA transcripts of MhRARl could be detected in all tested tissues and that expression was higher in leaves than that in stems and roots (Fig.4)

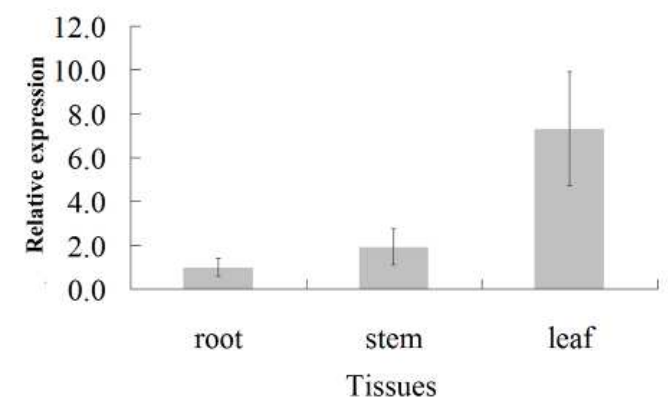

Fig. 4. Expression patterns of MhRAR1 in different tissues using qRT-PCR in M. hupehensis. MhTubulin transcript levels were used to normalise the samples. The mean value and standard deviation were obtained from three independent experiments.

\subsection{Expression of the MhRAR1 Gene Induced by SA, MeJA and ACC in Leaves, Stems and Roots of M. hupehensis}

In order to find out whether exogenous application of these stimuli could induce the expression of MhRARl gene, $M$. hupehensis leaves were treated by plant hormones like as SA, MeJA and ACC. The expressions of MhRARl gene in different organs of $M$. hupehensis were performed using qRT-PCR (Fig 5). SA, MeJA and ACC could induce the expression of MhRARl gene in stems (Fig 5D, E and F) and roots (Fig 5G, H and I), but not in leaves (Fig 5A, B and C).

The amount of height of the expression level varied substantially with both time and tissue. In leaves, the transcript levels had not obviously changed upon treatment with SA (Fig 5A), MeJA (Fig 5B) and ACC (Fig 5C) during the first $48 \mathrm{~h}$. In stems after 4,12 and $48 \mathrm{~h}$, the transcript levels rose $2.03 \mathrm{x}, 2.64 \mathrm{x}$ and $2.75 \mathrm{x}$, respectively, upon treatment with $\mathrm{SA}$, relative to the control treatment (Fig 5D). When stems were treated with MeJA, transcript levels of MhRARl rose $0.86 \mathrm{x}, 2.54 \mathrm{x}$ and $1.87 \mathrm{x}$ after the same time periods, respectively (Fig $5 \mathrm{E}$ ). Increases of $0.88 \mathrm{x}, 1.50 \mathrm{x}$ and $1.65 \mathrm{x}$ were observed in stems following ACC treatment after 4, 12 and $48 \mathrm{~h}$ (Fig 5F). In roots, when compared to measurements at time 0 of the experiment, the accumulation of MhRAR1 gene transcripts was $5.43 \mathrm{x}, 2.29 \mathrm{x}$ and $2.08 \mathrm{x}$ with SA (Fig 5G); $2.51 \mathrm{x}, 2.93 \mathrm{x}$ and $2.53 \mathrm{x}$ with MeJA (Fig $5 \mathrm{H}$ ); 4.23x, 8.42x and $2.02 \mathrm{x}$ with ACC (Fig 5I), 4, 12 and 48 h post-treatment, respectively. 


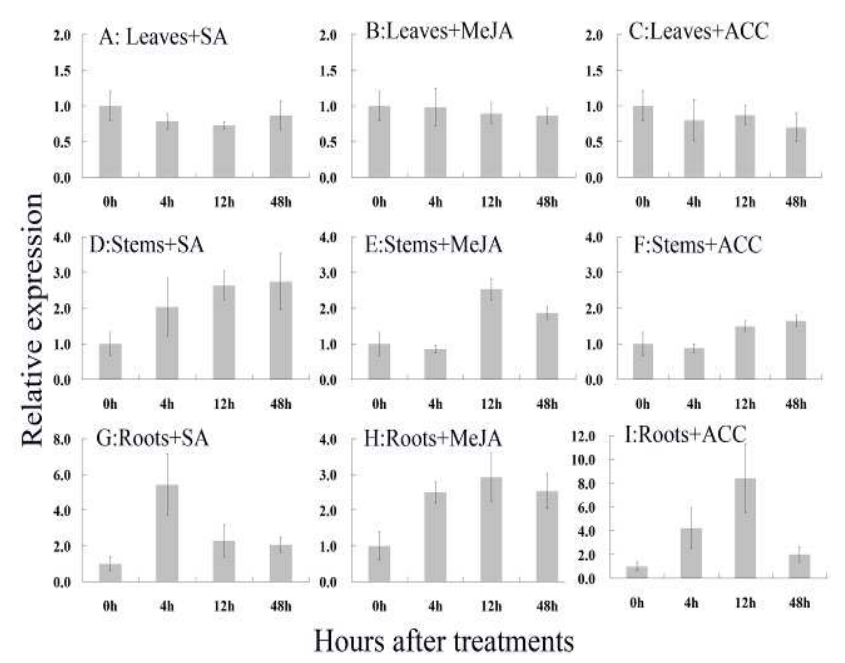

Fig. 5. Expression patterns of the MhRAR1 using qRT-PCR in M. hupehensis upon treatment with $S A$ ( $A, D$ and $G), M e J A(B, E$ and $H)$ and $A C C(C, F$ and I) in leaves $(A, B$ and $C)$, stems (D, E and $F)$ and roots $(G, H$ and $I)$, respectively. MhTubulin transcript levels were used to normalise the samples. Mean values and standard deviations were obtained from three independent experiments.

\subsection{Induction of the MhRAR1 Gene with the Fungus B. Berengeriana}

In this study, we analysed the change in the expression levels of the MhRARl gene in M. hupehensis post-infection with apple ring spot pathogen and showed that this pathogen could weakly induce the expression of MhRARl (Fig 6). Levels rose at 6 hours post-inoculation (hpi), remained at the highest level at $12 \mathrm{hpi}$, and then decreased (Fig 6).

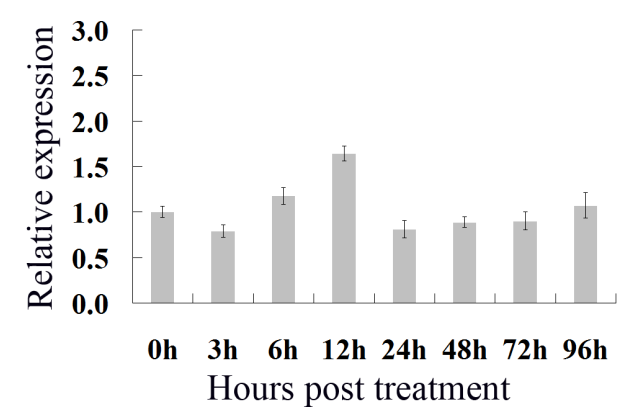

Fig. 6. Expression patterns of MhRARl using $q R T-P C R$ in M. hupehensis after inoculation with apple ring spot pathogen (Botryosphaeria berengeriana de Not. f. sp. Parabola Nise Koganezawa et Sakuma). Mean values and standard deviations were obtained from three independent experiments.

\subsection{Subcellular Localisation of MhRAR1 Protein}

To study the subcellular distribution of the MhRAR1 protein, the coding region of MhRAR1 without the stop codon was fused to EGFP under the control of the CaMV35S promoter (D35S::MhRAR1-GFP) in the experiment (Fig. 7a). This plasmid, or a control (D35S::GFP), was transformed into onion epidermal cells by the particle bombardment method. It could be observed that the control proteins were uniformly distributed in cells (Fig. 7b, B1 to B3), while the MhRAR1-EGFP fusion protein was located in the cell wall and cell membrane (Fig. 7b, A1 to A3).

(a)

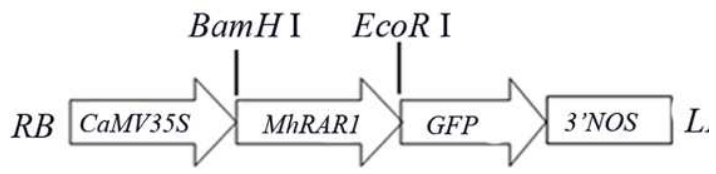

(b)

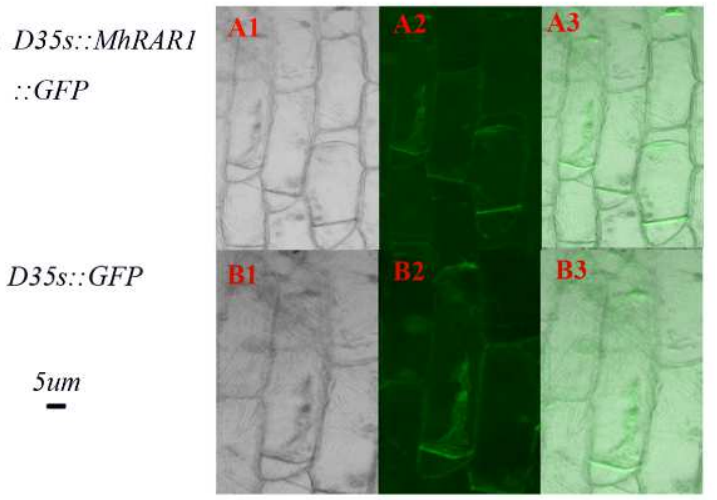

Fig. 7. The (a) MhRAR1 fusion GFP expression vector and (b) subcellular localisation of MhRAR1 in onion epidermal cells. Onion epidermal cells were transformed with D35S:MhRAR1-EGFP (A1 to A3) or the control plasmid D35S: EGFP (B1 to B3) using the particle bombardment method. The expression and subcellular distribution of proteins were examined under a light microscope $(A 1, B 1)$ or fluorescent microscope $(A 2, B 2)$ and then merged $(A 3, B 3)$. Data shown are representative of three independent experiments. EGFP: enhanced green fluorescent protein.

\section{Discussion}

RAR1 protein contains two highly similar zinc-binding domains named CHORD-I and CHORD-II that are conserved in eukaryotic phyla except yeast [26]. There are six conserved Cys and three conserved His in CHORD-containing proteins[6]. The tandem organization of CHORD domains and conserved primary structure suggested that these proteins supply important cellular functions. In additional, plant RAR1 proteins have a 20 -amino acid motif with three conserved Cys residues and a His residue in $\mathrm{CCCH}$ domain which was between CHORD domains I and II [4]. A cDNA sequence named MhRAR1 gene was isolated from the woody plant $\mathrm{M}$. hupehensis in this paper. Analysis of RAR1 protein sequence showed that MhRAR1 protein has high sequence similarly with other herbaceous plants, such as A. thaliana, N. tabacum, T. aestivum and so on. The same as these plants, $M$. hupehensis MhRAR1 protein also has two 60 aa long repeat motifs named CHORD domains at the $\mathrm{N}$ and $\mathrm{C}$ terminus, comprising about $50 \%$ of the predicted full length protein. Comparison of deduced protein sequence of M. hupehensis RAR1 gene with $R$. communis, A. thaliana, G. $\max , N$. tabacum, H. vulgare, T. aestivum and Saccharum hybrid cultivar showed the same tandem organization of the 60 aa motif as well as similar spacing in each species. And MhRAR1 contains conserved strings of invariant Cys and His residues within the $\mathrm{CHORD}$ domains. In additional, MhRAR1 protein possesses a $\mathrm{CCCH}$ domain which also has three conserved Cys and one His between the CHORD domains. As a result, we suggested that MhRAR1 protein maybe shared the similar function with the $A$. thaliana AtRAR1and $H$. vulgare 
HvRAR1, and is an important component of R gene-mediated disease resistance.

In this report, $M$. hupehensis leaves were treated by plant hormones like as SA, MeJA and ACC to understand whether exogenous application of these stimuli could induce the expression of MhRARl gene. The results showed that SA, MeJA and ACC could induce the expression of MhRAR1 gene in stem (Fig 5D, E and F) and $\operatorname{root}$ (Fig 5G, H and I), but not in leaf (Fig 5A, B and C), suggesting that the expression pattern of MhRARl gene in various tissues under the treatment with SA, MeJA or ACC were different.

Plant innate immune responses were triggered by $\mathrm{R}$ genes upon pathogen attack. RAR1, which was engage by various $R$ genes, is an early union point in a signaling pathway [11]. In plants, RAR1 interacts directly with SGT1 (for suppressor of the G2 allele of skp1) and HSP90 [2,8,12,27,28]. Cytosolic HSP90 contains three distinct domains: (1) an N-terminal ATPase domain $(\mathrm{N})$; (2) a substrate binding domain in the middle; (3) the $\mathrm{C}$-terminal end $(\mathrm{C})$ containing a dimerization domain and a MEEVD motif that binds tetratricopeptide repeat (TPR) domains of many cochaperones [8]. Takahashi et al [8] indicated that The CHORD-I domain of RAR1 interacts directly with the $\mathrm{N}$ terminus of HSP90. RAR1 physically interacts with SGT1 (suppressor of the G2 allele of SKP1) through the C-terminal CHORD-II of RAR1 and the central CS domain of SGT1 [2,29,30]. Azevedo et al [2] state clearly that the interactions among RAR1, SGT1 (suppressor of the G2 allele of SKP1), SCF (Skp1-CullinĐF-box), and signalosome subunits indicate a link between disease resistance and ubiquitination. In this study, the result of subcellular localisation showed that MhRAR1-EGFP fusion protein was located in the cell wall, cell membrane and cytoplasm, suggesting that MhRAR1 protein could interact with SGT1 and HSP90 in cytoplasm. In future, we will isolate the sequences of SGT1 and HSP90 from M. hupehensis to study whether SGT1 and HSP90 act with RAR1.

In plants, a major form of resistance to disease caused by microbial pathogens is by expression of complementary gene pairs in the plant and pathogen, known respectively as resistance $(R)$ and avirulence (avr) genes [31]. Direct or indirect interaction of their products activates cellular defenses that prevent pathogen colonization of the plant [32]. The most plant $R$ gene class encodes predicted cytosolic proteins with a central nucleotide binding (NB) domain and C-terminal Leu-rich repeats (LRRs) [31]. NB-LRR proteins fall into two subclasses based on their different $\mathrm{N}$-terminal motifs. One group possesses an N-terminal coiled-coil (CC) domain. The second group has N-terminal similarity to the cytoplasmic Toll Interleukin-1 Receptor (TIR) domains of human and Drosophila Toll-like receptors [31]. Muskett et al [4] reported that RAR is required by TIR- and CC-NB-LRR R genes. Barley RARl is a necessary component of $R$ gene-mediated resistance to the powdery mildew fungus [32]. In this study, the expression of MhRARl gene was induced by the apple ring spot pathogenesis. We conjecture that MhRAR1 maybe a necessary component of $\mathrm{R}$ gene--mediated resistance to the apple ring spot pathogenesis.

\section{Conclusion}

In this study, a novel RAR1 gene $M h R A R 1$ was cloned from $M$. hupehensis. The results showed that MhRAR1 protein contains two CHORD domains and one plant-specific $\mathrm{CCCH}$ domain. In addition, the MhRAR1 contains conserved strings of invariant cysteine and histidine residues within the CHORD domains and $\mathrm{CCCH}$ domain. These results suggested that MhRAR1 protein from $M$. hupehensis might share the similar function with the Arabidopsis thaliana RAR1 and $H$. vulgare RAR1, and is an important component of R gene-mediated disease resistance. Phylogenetic analysis revealed that MhRAR1 was closely related to $R$. communis RAR1. The expression of MhRARl gene was higher in leaves than that in stems and roots. SA, MeJA and ACC treatment induced MhRARl expression in stems and roots, but not in leaves. Expression of MhRARl was weakly induced in M. hupehensis after infection with Botryosphaeria berengeriana. In future studies we will concentrate on introducing the MhRARl gene into the 'Fuji' apple variety to determine if this can enhance resistance to apple plant pathogens, such as apple ring spot, apple powdery mildew and apple canker pathogens.

\section{Acknowledgements}

This work was supported by grants from the China Ministry of Science and Technology "863" program \# 2011AA100204 and National Natural Science Foundation of China \#31401854

\section{References}

[1] Shirasu K., Schulze-Lefert P. 2000. Regulators of cell death in disease resistance. Plant Molecular Biology 44: 371-385

[2] Azevedo C., Sadanandom A., Kitagawa K., Freialdenhoven K., Shirasu A., Schulze-Lefert P. 2002. The RAR1 Interactor SGT1, an Essential Component of $\mathrm{R}$ Gene-Triggered Disease Resistance. Science 295: 2073-2076

[3] Bieri S., Mauch S., Shen Q.H., Peart J., Devoto A., Casais C., Francesca C., Schulze S., Steinbiß H-H., Shirasu K., Schulze-Leferta P. 2004. RAR1 Positively Controls Steady State Levels of Barley MLA Resistance Proteins and Enables Sufficient MLA6 Accumulation for Effective Resistance. The Plant Cell Online 16: 3480-3495

[4] Muskett P.R., Kahn K., Austin M.J., Moisan L.J., Sadanandom A., Shirasu K., Jones J.D.G., Parker J.E. 2002. Arabidopsis RAR1 Exerts Rate-Limiting Control of $\mathrm{R}$ Gene-Mediated Defenses against Multiple Pathogens. The Plant Cell Online 14: 979-992

[5] Tornero P., Merritt P., Sadanandom A., Shirasu K., nnes R.W.I., Dangl J.L. 2002. RAR1 and NDR1 Contribute Quantitatively to Disease Resistance in Arabidopsis, and Their Relative Contributions Are Dependent on the R Gene Assayed. The Plant Cell Online 14: 1005-1015

[6] Shirasu K., Lahaye T., Tan M-W., Zhou F., Azevedo C., Schulze-Lefert P. 1999. A novel class of eukaryotic zinc-binding proteins is required for disease resistance signaling in barley and development in C. elegans. Cell 99: 355-366 
[7] Shang Y., Li X., Cui H., He P., Thilmony R., Chintamanani S., Zwiesler-Vollick J., Gopalan S., Tang X., Zhou J.M. 2006. RAR1, a central player in plant immunity, is targeted by Pseudomonas syringae effector AvrB. Proceedings of the National Academy of Sciences 103: 19200-19205

[8] Takahashi A., Casais C., Ichimura K., Shirasu K. 2003. HSP90 interacts with RAR1 and SGT1 and is essential for RPS2-mediated disease resistance in Arabidopsis. Proceedings of the National Academy of Sciences 100: 11777-11782

[9] Tai Y.S. 2007. Interactome of signaling networks in wheat: the protein-protein interaction between TaRAR1 and TaSGT1. Molecular Biology Reports 35: 337-343

[10] Zellerhoff N., Jansen M., Schaffrath U. 2008. Barley Rom1 antagonizes Rar1 function in Magnaporthe oryzae-infected leaves by enhancing epidermal and diminishing mesophyll defence. New Phytologist 180: 702-710

[11] Zhang L., Yang W., Liu D. 2011. TaRAR1 is Required for Lr24-Mediated Wheat Leaf Rust Resistance. Agricultural Sciences in China 10: 1732-1738

[12] Liu Y., Schiff M., Marathe R., Dinesh-Kumar S.P. 2002. Tobacco Rar1, EDS1 and NPR1 NIM1 like genes are required for $\mathrm{N}$ mediated resistance to tobacco mosaic virus. The Plant Journal 30: 415-429

[13] Glazebrook J. 2001. Genes controlling expression of defence responses in Arabidopsis- 2001 status. Curr Opin Plant Biol 4:301-308

[14] Kim J.C., Lee S.H., Cheong Y.H., Yoo C.M., Lee S.I., Chun H.J., Yun D.J., Hong J.C., Lee S.Y., Lim C.O., Cho M.J. 2001. A novel cold-inducible zinc finger protein from soybean, SCOF-1, enhances cold tolerance in transgenic plants. Plant $\mathrm{J}$ $25: 247-251$

[15] Dong X. 1998. SA, JA, ethylene, and disease resistance in plants. Curr.Opin. Plant Biol 1:316-323

[16] Spoel S.H., Koornneef A., Claessens S.M., Korzelius J.P., Pelt J.A., Mueller M.J., Buchala A.J., Metraux J.P., Brown R., Kazan K., Loon L.C., Dong X.N., Pieterse C.M. 2003. NPR1 modulates cross-talk between salicylate- and jasmonate-dependent defense pathways through a novel function in the cytosol. The Plant Cell 15:760-770

[17] Leon-Reyes A., Spoel S.H., Lange E.S., Abe H., Kobayashi M., Tsuda S., Millenaar F.F., Welschen R.A., Ritsema T., Pieterse C.M. 2009. Ethylene modulates the role of nonexpressor of pathogenesis-related genes 1 in cross talk between salicylate and jasmonate signaling. Plant Physiology 149:1797-1809

[18] Lu Q.N., Jia D.X. 1999. China Fruit Records: Apple Volume, First Ed., China's Agricultural Science \& Technology Press, Beijing

[19] Zhang J.Y., Qu S.C., Dong C., Gao Z.H., Qiao Y.S., Zhang Z. 2010. Utility and construction of full-length cDNA library of Malus hupehensis post-introduced with salicylic acid. Acta Bot Boreal -Occident. Sin 30 (8):1527-1533
[20] Tong Z.G., Wang F.R., Zhang Z., Zhao J.B., Zhang K.C., Yan G.H., Zhou Y., Jiang L.J. 2008. A method for DNA extraction from mature leaves of fruit trees. J. Fruit Sci. 25, 122-125

[21] Tamura K., Dudley J., Nei M., Kumar S. 2007. MEGA4: Molecular evolutionary genetics analysis (MEGA) software version 4.0. Mol Biol Evol 24:1596-1599

[22] Page R.D. 1996. Tree view: an application to display phylogenetic trees on personal computers. Comput Appl Biosci $12: 357-358$

[23] Cai B.H., Zhang J.Y., Gao Z.H., Qu S.C., Tong Z.G., Mi L., Qiao Y.S., Zhang Z. 2008. An improved method for isolation of total RNA from the leaves of Fragaria spp. Jiangsu Journal of Agricultural Sciences. 24, 875-877

[24] Livak K.J., Schmittgen T.D. 2001. Analysis of Relative Gene Expression Data Using Real-Time Quantitative PCR and the 2- $\Delta \Delta$ CT Method. Methods 25: 402-408

[25] Wang Q.J., Xu K.Y., Tong Z.G., Wang S.H., Gao Z.H., Zhang J.Y., Zong C.W., Qiao Y.S., Zhang Z. 2010. Characterization of a new dehydration responsive element binding factor in central arctic cowberry. Plant Cell, Tissue and Organ Culture (PCTOC) 101: $211-219$

[26] Wu J., Luo S., Jiang H., Li H. 2005. Mammalian CHORD-containing protein 1 is a novel heat shock protein 90-interacting protein. FEBS Letters 579: 421-426

[27] Thao N.P., Chen L., Nakashima A., Hara S., Umemura K., Takahashi A., Shirasu K., Kawasaki T., Shimamoto K. 2007. RAR1 and HSP90 Form a Complex with Rac/Rop GTPase and Function in Innate-Immune Responses in Rice. The Plant Cell Online 19: 4035-4045

[28] Zhang M., Kadota Y., Prodromou C., Shirasu K., Pearl L.H. 2010. Structural Basis for Assembly of Hsp90-Sgt1-CHORD Protein Complexes: Implications for Chaperoning of NLR Innate Immunity Receptors. Molecular Cell 39: 269-281

[29] Eitas T.K., Nimchuk Z.L., Dangl J.L. 2008. Arabidopsis TAO1 is a TIR-NB-LRR protein that contributes to disease resistance induced by the Pseudomonas syringae effector AvrB. Proceedings of the National Academy of Sciences of the USA, 105: 6475-6480

[30] Hubert D.A., He Y., McNulty B.C., Tornero P., Dangl J.L. 2009 Specific Arabidopsis HSP90.2 alleles recapitulate RAR1 cochaperone function in plant NB-LRR disease resistance protein regulation. Proceedings of the National Academy of Sciences 106: 9556-9563

[31] Dangl J.L., Jones J.D. 2001. Plant pathogens and integrated defence responses to infection. Nature 411: 826-833

[32] Austin M.J., Muskett P., Kahn K., Fey B.J., Jones J.D.G., Parker J.E. .2002. Regulatory Role of SGT1 in Early R Gene-Mediated Plant Defenses. Science 295: 2077-2080 